\title{
Developing Local Coastal Adaptation Strategies to Climate Change across North West Europe: How IMCORE is addressing the Challenges
}

\author{
Val Cummins, MERC 3 National Maritime College of Ireland
}

There are a number of challenges in developing effective local adaptation strategies to climate change ranging from lack of public awareness of potential impacts through to lack of capacity and resources in local authorities. IMCORE (Innovative Management for Europe's Changing Coastal Resource), (INTERREG IVB), is applying various techniques to overcome these challenges at nine sites across North West Europe. This entails identifying the potential impacts of a range of climate change scenarios on coastal sectors (e.g. fisheries and aquaculture, ports and shipping, marine recreation and coastal protection) and subsequently developing an effective response in the form of adaptive management strategies at each site. Site specific issues associated with these sectors are also being considered and these include: coastal conservation, marine spatial planning, integration of decision making across sectors, coastal regeneration, renewable energy, public participation and marine biodiversity.

The Project actively promotes partnership between research centres and local authorities who are working in tandem to address local issues thus avoiding the very real risk of perpetuating the disconnect that exists between the scientific output and the needs of local government. IMCORE advocates an ecosystem approach to management and therefore considers not just the environmental impacts but also the economic and social consequences that may result from the impacts of climate change.

This paper will provide an overview of the project, present reasons why adaptation is necessary and highlight the key challenges to developing strategies. Using the ongoing development of the Cork Harbour adaptive management strategy as an example it will demonstrate how the innovative approach employed by IMCORE s being utilized to address these challenges. 